\title{
A High-Performance SiGe-Si Multiple-Quantum-Well Heterojunction Phototransistor
}

\author{
Zingway Pei, C. S. Liang, L. S. Lai, Y. T. Tseng, Y. M. Hsu, P. S. Chen, S. C. Lu, M.-J. Tsai, and \\ C. W. Liu, Senior Member, IEEE
}

\begin{abstract}
A novel phototransistor is fabricated by placing $\mathrm{Si}_{0.5} \mathbf{G e}_{0.5} / \mathrm{Si}$ multiple quantum wells (MQWs) between the base and the collector of $\mathrm{Si}-\mathrm{SiGe}$ heterojunction bipolar transistors (HPT). The SiGe-Si MQWs are used as a light absorption layer. The cutoff frequency $\left(f_{T}\right)$ and maximum oscillation frequency ( $f_{\mathrm{MAX}}$ ) of the phototransistor are found to be $25 \mathrm{GHz}$, which is suitable for gigabit integrated circuit. The responsivity of $1.3 \mathrm{~A} / \mathrm{W}$ (external quantum efficiency $=194 \%$ ) and the pulsewidth of 184 ps at a wavelength of $850 \mathrm{~nm}$ are observed. The excellent electrical and optical performance of the Si-SiGe MQW phototransistor makes it attractive for future $\mathrm{Si}$-based optoelectronic integrated circuit applications.
\end{abstract}

Index Terms-Multiple quantum wells (MQWs), phototransistors, SiGe.

\section{INTRODUCTION}

$\mathbf{I}$ N RECENT years, the Si-based photodetector with high responsivity, high speed, and low cost has been attractive for high-speed optoelectronic integrated circuit applications [1], [2]. To achieve the high response, the thick absorption layer as compared to absorption length is commonly used for absorbing the incident light. It is well known that $\mathrm{Si}$ has absorption depth of $\sim 20 \mu \mathrm{m}$ at an 850-nm wavelength. However, the thick absorption layer increases the carrier transit time and degrades the speed [3]. Therefore, the tradeoff between the responsivity and the speed has to be considered in conventional structures [4], [5]. It is reported [6], [7] that the photodetector using a deep trench structure, where the photo carriers are transported laterally to decrease the carrier transit time, has a bandwidth of $2 \mathrm{GHz}$ and responsivity of $0.35 \mathrm{~A} / \mathrm{W}$ at 850 $\mathrm{nm}$ with the tradeoff between the response and the speed. A resonant cavity structure was used to increase the responsivity at specific wavelength (such as $850 \mathrm{~nm}$ ) with proper cavity design. Therefore, resonant cavity photodetector could have high speed and efficiency at designed wavelength. However, the control on the resonant wavelength by cavity thickness is difficult [8], [9]. A small deviation on the layer thickness

Manuscript received July 21, 2003; revised August 4, 2003. The review of this letter was arranged by Editor P. Yu.

Z. Pei, C. S. Liang, L. S. Lai, Y. T. Tseng, Y. M. Hsu, P. S. Chen, S. C. Lu, and M.-J. Tsai are with the Electronics Research and Service Organization (ERSO), ITRI, Hsinchu, Taiwan, R.O.C.

C. W. Liu is with the Electronics Research and Service Organization (ERSO), ITRI, Hsinchu, Taiwan, R.O.C. and also with the Department of Electrical Engineering, National Taiwan University, Taipei, Taiwan, R.O.C. (e-mail: zingway@ itri.org.tw).

Digital Object Identifier 10.1109/LED.2003.817870 will degrade the resonant absorption at demanded wavelength $(850 \mathrm{~nm})$. The absorption layer using the waveguide structure, where the light is absorbed laterally, can also increase the responsivity as a result of the long absorption path [10]. This structure can have high speed because the carrier is transport perpendicular to the light absorption direction with the thin absorption layer. However, the small area for optical coupling in the waveguide structure will cause large insertion loss and requires complex optical alignment technique. This limits the low-cost applications. A heterojunction bipolar phototransistor (HPT) has been reported with high responsivity and high speed simultaneously on compound semiconductor [11], [12]. In this letter, a novel SiGe-Si multiple-quantum-well (MQW) HPT with high responsivity, high speed, and potential of monolithic integration has been presented.

\section{DEVICE FABRICATION}

The phototransistor was fabricated by a baseline process of heterojunction bipolar transistor (HBT) with $f_{T}=50 \mathrm{GHz}$ [14]. Five periods of undoped $\mathrm{Si}_{0.5} \mathrm{Ge}_{0.5}(5 \mathrm{~nm}) / \mathrm{Si}(25 \mathrm{~nm})$ multiple quantum wells MQWs were grown between the base and the collector by an ultrahigh-vacuum chemical vapor deposition (UHVCVD) system as absorption layers [13]. To achieve the high-speed HBT characteristics, the SiGe base was 60 -nm-thick with the first $30 \mathrm{~nm}$ consisting of $15 \% \mathrm{Ge}$ and then graded decline to zero for the following $30 \mathrm{~nm}$ to achieve short base transit time. The boron doping concentrations were $5 \times 10^{18} \mathrm{~cm}^{-3}$ in the graded base region. $\mathrm{Si} H_{4}$ and $\mathrm{Ge}_{4}$ were used as the $\mathrm{Si}$ and Ge precursors, respectively, with the growth temperature of $550{ }^{\circ} \mathrm{C}$. Arsenic implanted poly-Si was used as the emitter [13], [14]. The HPT has an emitter area of $0.6 \times 10 \mu \mathrm{m}^{2}$ and an optical opening of $14.4 \mu \mathrm{m}^{2}$ through the base-collector junction.

\section{RESULTS AND DISCUSSION}

Fig. 1 shows the Gummel plot of the Si-SiGe MQW phototransistor. It is observed that the base current $\left(I_{b}\right)$ is nearly ideal with $V_{\mathrm{BE}}>0.5 \mathrm{~V}$ and the high electrical current gain of 200 is achieved at $V_{\mathrm{BE}}=0.66 \mathrm{~V}$. The inset of Fig. 1 shows the measured $f_{T}$ of phototransistor is $25 \mathrm{GHz}$, which is smaller than the control HBT $(48 \mathrm{GHz}$ ) due to the additional SiGe MQWs. The $f_{\text {MAX }}$ of the phototransistor is $25 \mathrm{GHz}$, which is larger than the 


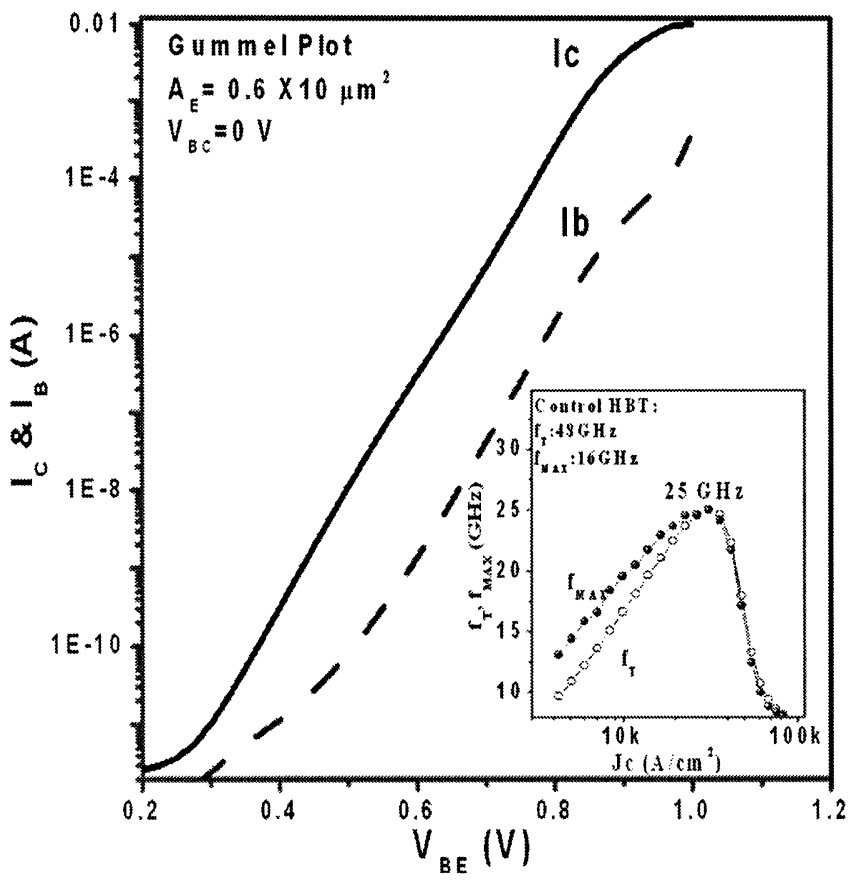

Fig. 1. Gummel plot of the MQW HPT. Inset shows the high-frequency properties.

control HBT (16 GHz) due to the decrease of base-collector capacitance by the undoped SiGe MQWs. The HPT still remains good dc and radio frequency (RF) properties in spite of the additional MQW absorption layers, which are enough to implement a Gbit transimpedance amplifier and other integrated circuit applications [15].

To investigate the photocurrent and responsivity of the phototransistor, we have used two modes: 1) emitter open configuration (photodiode mode) and 2) base open configuration (HPT mode). In case of photodiode mode, the phototransistor shows the low dark current of $10 \mathrm{pA}$ at $3 \mathrm{~V}$ and exhibits $4.6-\mu \mathrm{A}$ photocurrent at $850-\mathrm{nm}$ light exposure with $180-\mu \mathrm{W}$ incident power (responsivity $\sim 26 \mathrm{~mA} / \mathrm{W}$ ). The low responsivity is due to the absorption layer (totally $0.15 \mu \mathrm{m}$ for $\mathrm{Si}-\mathrm{SiGe} \mathrm{MQWs}$ ) is much thinner than the long absorption length of $\mathrm{Si}_{0.5} \mathrm{Ge}_{0.5}(3 \mu \mathrm{m})$ for 850-nm wavelength light absorption. Under HPT mode, photocurrent is largely enhanced to $235 \mu \mathrm{A}$ at $V_{\mathrm{CE}}=3 \mathrm{~V}$, while the dark current still remains low $(100 \mathrm{pA})$. The responsivity of SiGe HPT exceeds $1 \mathrm{~A} / \mathrm{W}$ for a wide range of applied voltage $(0.4-3 \mathrm{~V})$ and has a high value of $1.3 \mathrm{~A} / \mathrm{W}$ at $V_{\mathrm{CE}}=3 \mathrm{~V}$ as seen in Fig. 2, while the control SiGe HBT without SiGe MQW is $0.7 \mathrm{~A} / \mathrm{W}$ [11]. The slightly increase for the photocurrent with the increase of the $V_{\mathrm{CE}}$ is due to the Early effect the same as in SiGe HBTs. It is noted that the photocurrent at HPT mode is amplified about 50 times as compared to photodiode mode and it has been explained in Fig. 3. Inset of the Fig. 2 shows the photocurrent versus optical power $(20-450 \mu \mathrm{W})$ at $V_{\mathrm{CE}}$ bias of 1,2 , and $3 \mathrm{~V}$, respectively, for a SiGe phototransistor. The near linear behavior and small signal detection ability $(20 \mu \mathrm{W})$ indicate that the phototransistor is adequate for optical communication.

The schematic band diagram of the $\mathrm{Si}_{0.5} \mathrm{Ge}_{0.5} / \mathrm{Si} \mathrm{MQWs}$ is shown in Fig. 3. The SiGe-Si MQWs can increase the light absorption as compared to $\mathrm{Si}$ layers due to the smaller bandgap of

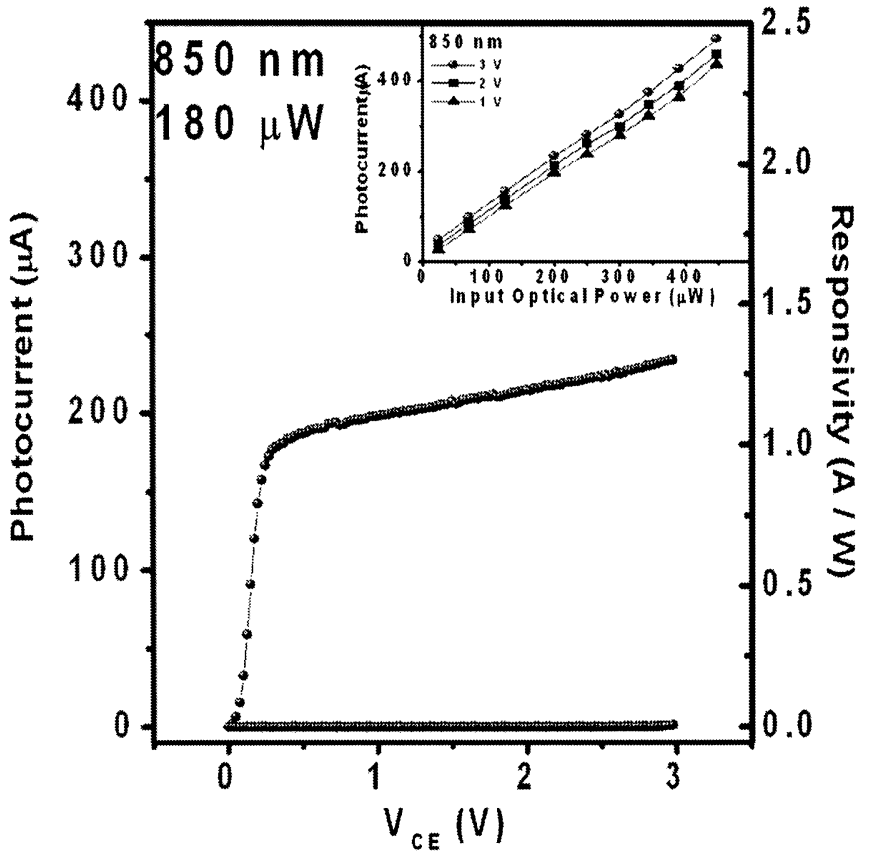

Fig. 2. Photocurrent and responsivity of the MQW HPT at 850-nm light illumination. Inset shows the photocurrent to input optical power relationship.

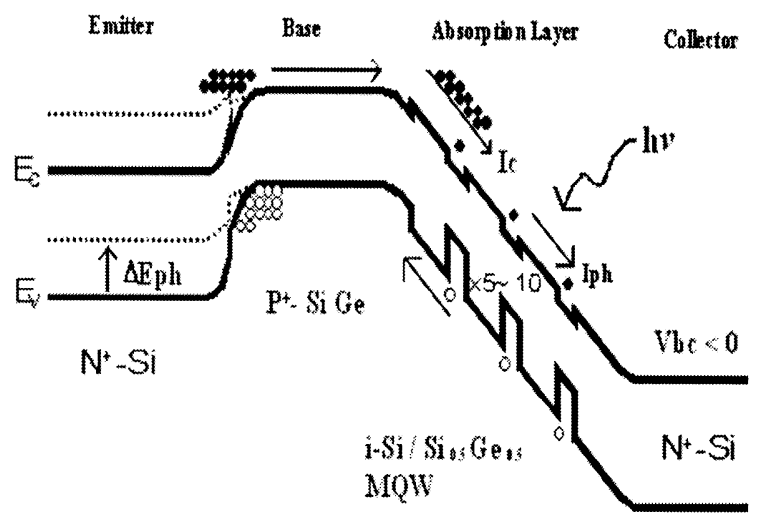

Fig. 3. Schematic band diagram of the SiGe-Si MQW phototransistor.

Ge. Both electrons and holes are generated in the base-collector region under light exposure, electrons are swept to the collector as parts of the initial photocurrent of the heterojunction phototransistor, and the generated holes diffuse to the base region and inject into the emitter by lowering the base-emitter energy barrier. The barrier lowering allows a large amount of electrons to diffuse across the base to the collector and amplifies the initial photo current. The photocurrent at collector was then largely enhanced.

High-speed temporal response of the SiGe MQW phototransistor is obtained by impulse response measurement. A 50-ps pulse laser output driven by a pulse generator at 850 -nm wavelength is coupled through a fiber to the phototransistor and a sampling oscilloscope records the response of phototransistor. Fig. 4 shows the pulse response of a SiGe phototransistor with different applied voltages ( $V_{\mathrm{CE}}=1,2$, and $3 \mathrm{~V}$, respectively). At $3 \mathrm{~V}$, the $\mathrm{SiGe}$ phototransistor has the rise time $\left(t_{r}\right)$ of 64 ps, fall time $\left(t_{f}\right)$ of $442 \mathrm{ps}$, and a full width at half maximum 


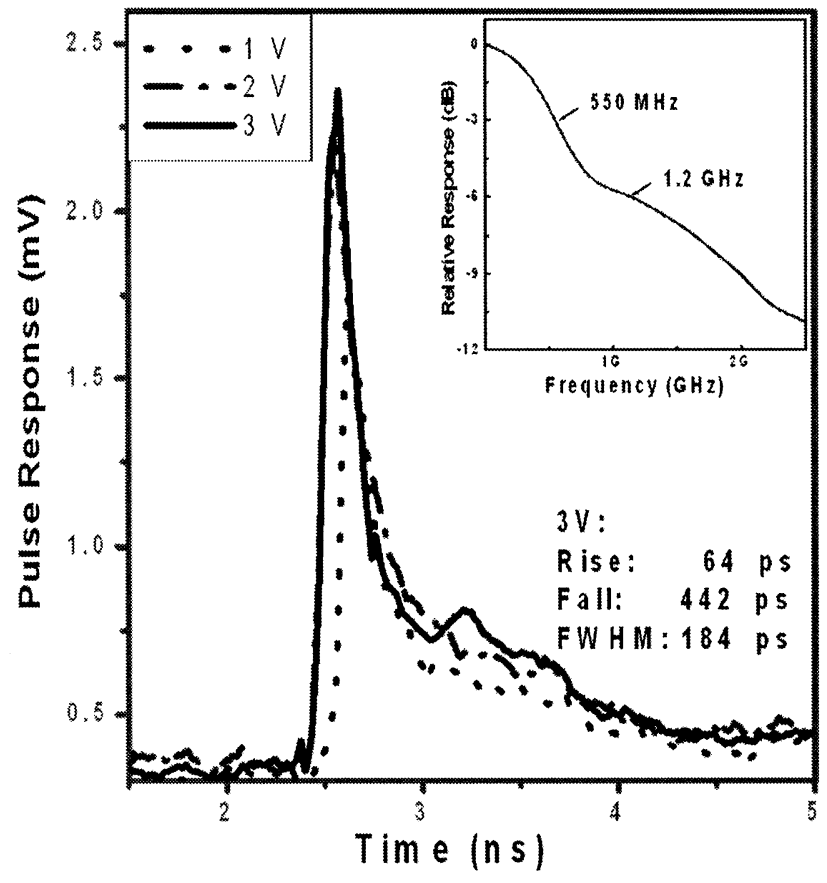

Fig. 4. Pulse response of SiGe HPT at 850-nm and 50-ps pulse laser illumination with the applied voltages of 1,2 , and $3 \mathrm{~V}$, respectively.

(FWHM) of 184 ps. After Fourier transform, the optical 3-dB bandwidth is about $550 \mathrm{MHz}$, which is limited by the long tail. In spite of the fast falling of the ac response at low frequency, the $6-\mathrm{dB}$ bandwidth is $\sim 1.2 \mathrm{GHz}$, which corresponds to the ac response one-half the initial value. The pulse response has fast rise time and slow two-step fall time for all operation voltages. In the falloff process, the two-step process can be further distinguished by a fast-fall process then a second slow process that results a long tail. The first-fall process could be described as the turn-off process of the phototransistor while the nonzero tail of the second fall time process is probably due to the slow diffusion and recombination of carriers generated from the Si substrate. The effect of the slow diffusion carriers could possible reduced by increasing the response of phototransistor or using silicon-on-insulator (SOI) substrate [7].

\section{SUMMARY}

In summary, we have reported the high-performance phototransistor with SiGe-Si MQWs. The Gummel plot of the phototransistor shows the high current gain of $\sim 200$ with the low junction-leakage current. The $f_{T}$ and $f_{\max }$ are observed to be $25 \mathrm{GHz}$. The phototransistor shows the high responsivity of 1.3 A/W with the external quantum efficiency of $194 \%$ and the pulsewidth of 184 ps with the operation voltage of $3 \mathrm{~V}$ at the wavelength of $850 \mathrm{~nm}$. Improved optical performance and the potential monolithic integration of the $\mathrm{Si}-\mathrm{SiGe}$ phototransistor pave the way for future high-speed Si-based optoelectronic integrated circuits.

\section{ACKNOWLEDGMENT}

The helpful suggestion and discussion from Dr. H. P. Hwang are gratefully acknowledged. The great support of Prof. Y. J. Chan from National Central University on pulse measurement is also acknowledged.

\section{REFERENCES}

[1] J.-S. Rieh, D. Klotzkin, O. Qasaimeh, L.-H. Lu, K. Yang, L. P. B. Katehi, P. Bhattacharya, and E. T. Croke, "Monolithically integrated SiGe-Si PIN-HBT front-end photoreceivers," IEEE Photon. Technol. Lett., vol. 10, pp. 415-417, Mar., 1998.

[2] H. Zimmermann and T. Heide, "A monolithically integrated 1- Gb/s optical receiver in 1- um CMOS technology," IEEE Photon. Technol. Lett., vol. 13, pp. 711-713, July 2001.

[3] M. B. Das, "Optoelectronic detectors and receivers: sSpeed and sensitivity limits," in Proc. Conf. Optoelectron. Microelectron. Mat. Devices, 1999, pp. 15-22.

[4] S. G. Thomas, S. Csutak, R. E. Jones, S. Bharatan, C. Jasper, R. Thomas, T. Zirkle, and J. C. Campbell, "CMOS-compatible photodetector fabricated on thick SOI having deep implanted electrodes," Electron. Lett., vol. 38 , no. 20, pp. 1202-1204, 2002.

[5] M. Ghioni, F. Zappa, V. P. Kesan, and J. Warnock, "A VLSI-compatible high-speed silicon photodetector for optical data link applications," IEEE Trans. Electron Devices, vol. 43, pp. 1054-1060, July 1996.

[6] M. Yang, K. Rim, D. L. Rogers, J. D. Schaub, J. J. Welser, D. M. Kuchta, D. C. Boyd, F. Rodier, P. A. Rabidoux, J. T. Marsh, A. D. Ticknor, Q. Tang, A. Upham, and S. C. Ramac, "A high-speed, high-sensitivity silicon lateral trench photodetector," IEEE Electron Device Lett., vol. 23, pp. 395-397, July 2002.

[7] M. Yang, J. Schaub, D. Rogers, M. Ritter, K. Rim, J. Welse, and B. Park, "High speed silicon lateral trench detector on SOI substrate," in IEDM Tech. Dig., 2001, pp. 547-550.

[8] J. D. Schaub, R. Li, C. L. Schow, J. C. Campbell, G. W. Neudeck, and J. Denton, "Resonant-cavity-enhanced high speed Si photodiode grown by epitaxial lateral overgrowth," IEEE Photon. Technol. Lett., vol. 11, pp. 1647-1649, Dec. 1999.

[9] M. K. Emsley, O. Dosunmu, and M. S. Unlu, "High-efficiency, $10 \mathrm{GHz}$ bandwidth resonant-cavity-enhanced silicon photodetectors operating at $850 \mathrm{~nm}$ wavelength," in Proc. Lasers Electro-Optics Soc., vol. 2, 2001, pp. $839-840$.

[10] T. Tashiro, T. Tatsumi, M. Sugiyama, T. Hashimoto, and T. Morikawa, "A selective epitaxial SiGe-Si planar photodetector for Si-based OEICs," IEEE Trans. Electron Devices, vol. 44, pp. 545-550, Apr. 1997.

[11] J. C. Campbell, "Phototransistors for lightwave communications," in Semiconductors and Semimetals, 1985, pt. D, vol. 22, ch. 5, pp. 389-447.

[12] H. Kamitsuna, Y. Matsuoka, S. Yamahata, and N. Shigekawa, "Ultrahigh-speed Inp-InGaAs DHPTS for OEMMIC," IEEE Trans. Microwave Theory Tech., vol. 49, pp. 1921-1925, Oct. 2001.

[13] Z. Pei, C. S. Liang, L. S. Lai, Y. T. Tseng, Y. M. Hsu, P. S. Chen, S. C. Lu, C. M. Liu, M.-J. Tsai, and C. W. Liu, "High efficient $850 \mathrm{~nm}$ and 1310 $\mathrm{nm}$ multiple quantum well $\mathrm{SiGe}-\mathrm{Si}$ heterojunction phototransistors with 1.25 plus GHz bandwidth $(850 \mathrm{~nm})$," in IEDM Tech. Dig., 2002, pp. 297-300.

[14] L. S. Lai, Y. T. Tseng, L. S. Lee, Y. S. Jean, Y. M. Hsu, H. P. Hwang, S. C. Lu, and M.-J. Tsai, "The high quality low temperature oxidation technology in a quasi self-aligned SiGe HBT," in Proc. Int. Symp. Electron Devices Microwave Optoelectron. Applicat., 2001, pp. 77-82.

[15] J.-S. Rieh, O. Qasaimeh, L.-H. Lu, K. Yang, L. P. B. Katehi, P. Bhattacharya, and E. T. Croke, "Single- and dual-feedback transimpedance amplifiers implemented by SiGe HBT technology," IEEE Microwave Guided Wave Lett., vol. 8, pp. 63-65, Feb. 1998. 